\title{
Program Overview of the Supplementary Food Intervention for Chronic Energy Deficiency Pregnant Women and Thin Toddlers of South Halmahera Regency in Indonesia
}

\author{
Nani Supriyatni ${ }^{1 *}$, Andiani ${ }^{1}$, Suryani Mansyur ${ }^{1}$, Diah Merdekawati ${ }^{1}$ \\ ${ }^{I}$ Faculty of Public Health, Universitas Muhammadiyah Maluku Utara, Jl. KH. Ahmad Dahlan 100 Kota \\ Ternate Selatan, 97719, Ternate, Indonesia \\ *Corresponding author. Email: naniskm@yahoo.com
}

\begin{abstract}
The nutritional status of toddlers in North Maluku Province in 2003-2017 shows that wasting has decreased from $16.1 \%$ in $2003,15.7 \%$ in 2013 , and $10.3 \%$ in 2017 . While the stunting condition has fluctuated from $25.4 \%$ in $2003,18.3 \%$ in 2013 , and $25 \%$ in 2017. Meanwhile, the stunting condition in South Halmahera Regency in 2017 was $28.4 \%$. Based on these conditions, the stunting in South Halmahera regency has increased. This study purpose of obtaining an overview the supplementary food and storage, the supplementary feeding impact on chronic energy deficiency (KEK) pregnant women and underweight toddlers, and supplementary food utilization for KEK pregnant women and underweight toddlers by the target. The study conducted by survey method, where the sample population was all KEK pregnant women and underweight toddlers who had received supplementary feeding in public health centres (Puskesmas) work areas of Labuha, Babang, Bibinoi, Loleo Jaya, Bajo, Jiko, Indong, Gandasuli, and Indari districts in South Halmahera regency. The sample was a purposive sampling of 45 underweight toddlers and 44 KEK pregnant women. The results showed that the majority of pregnant women age early receiving supplementary food was in trimester 2 and 3 of $63.6 \%$, and the rest were in trimester 1 of $36.4 \%$. After supplementary food interventions for 1-3 months, pregnant women with good health conditions of $45.5 \%$, while Chronic Energy Deficiency (KEK) conditions of 54.5\%. Pregnant women who experienced a weight gain of $77.3 \%$ and $22.7 \%$ did not gain. Meanwhile, the nutritional status of underweight toddlers (BB/U) after consuming, 28.9\% experienced a minimum increase in weight according to BB/U (proper nutrition), and $71.1 \%$ experienced under nutrition. Furthermore, Toddler weight gain was $93.3 \%$ and did not experience an increase of $6.7 \%$. While the impact of supplementary feeding on weight gain of underweight toddlers is $28.9 \%$, whose condition has improved, and $71.1 \%$ are still malnutrition. However, $93.3 \%$ experienced a weight increase. Therefore, the people concern need and joint support for KEK pregnant women and underweight toddler problems by attention food intake, environmental sanitation, and basic health services, and supplementary feeding counselling for pregnant women and toddler programs.
\end{abstract}

Keywords: chronic, energy, deficiency, stunting

\section{INTRODUCTION}

In 2013 Riskesdas known that the underweight children and stunting toddler prevalence were $12.1 \%$ and $37.2 \%$ respectively, while chronic energy deficiency (KEK) risk pregnant women prevalence was $24.2 \%$. Besides, the nutrition data for children aged 5-12 years was $11.2 \%$ due to not having breakfast and preferring foods less nutritious foods. Nutrition Status Monitoring (PSG) results in 2016 showed that the stunting toddlers stunting prevalence were $27.5 \%$, thin toddlers $8.0 \%$, skinny $3.1 \%$, and thin toddlers risk $22.8 \%$. Meanwhile, the stunting cases number of North Maluku province is still 11th ranked.

Disorders growth and development problems in infants and children under two years aged (Baduta) is a problem that needs to be taken seriously (1). Under two years aged is a significant period as well as rheumatoid arthritis in children growth and development process both physically and intelligence (2) (3). Lack and stunting at school age will have an impact on school performance, which in turn will affect human resources quality. Pregnant women with KEK 
status can affect the growth and health of their babies (4) (5).

Supplementary feeding, especially for vulnerable groups, is one of the supplementation strategies in overcoming nutritional problems. Based on 2014 total diet survey (SDT) data, it is known that more than half under-five children $(55.7 \%)$ have less energy intake than the recommended Energy Adequacy Rate (AKE) (6). In pregnant women group, both in rural and urban areas, more than half have deficits in energy and protein intake (7). Based on this condition, supplementary feeding that focuses both on macro-nutrients and micro-nutrients for toddlers and pregnant women is urgently needed to prevent low birth weight (LBW) and stunting whereas supplementary feeding to old school children is needed to increase nutritional intake to support nutritional needs at school (8) (9). The supplementary feeding target is given to nutrition-prone group which includes 6-59 months, thin toddlers and elementary school who are based on weight measurements results according to body length/height less than the minimum two standard deviations $(<-2 \mathrm{Sd})$, as well as KEK risk pregnant women ie, pregnant women with measurement results of upper arm circumference (LiLA) smaller than $23.5 \mathrm{~cm}$.

Based on North Maluku Provincial Health Office data, it is known that children under five nutritional status of wasting $16.1 \%$ (2003), $15.7 \%$ (2013) and $10.3 \%$ (2017), while for stunting $25.4 \%$ (2003), 18,3\% (2013) and 25\% (2017), whereas South Halmahera Regency data in 2017 stunting was $28.4 \%$. It is known that South Halmahera Regency for stunting data has increased so that there is a program intervention need for supplementary feeding problem of KEK pregnant women and skinny toddlers. Therefore, the study aims to obtain the Supplementary Food (MT) distribution; overview, storage, impact on Weight (BB) increase of KEK pregnant women, gain weight (BB) impact of under-five underweight, utilization to pregnant women KEK and under-fives by the target.

\section{METHOD}

The population in the survey were all KEK pregnant women and underweight toddlers who had received additional food in the work areas of the Labuha, Babang, Bibinoi, Loleo Jaya, Bajo, Jiko, Indong, Gandasuli and Indari Puskesmas in South Halmahera District. The sample in this survey used purposive sampling with inclusion criteria KEK pregnant women and thin toddlers who had received program supplementary food from the health centre as many as 45 under-fives and $44 \mathrm{KEK}$ pregnant women. Therefore, total respondents were 89 people.

\section{RESULTS AND DISCUSSION}

Results of Supplementary Food Monitoring for Pregnant Women with Chronic Energy Deficiency (KEK) in South Halmahera Regency

The respondents of pregnant women who experienced less chronic energy (KEK) previously in South Halmahera District and received supplementary food were more in the productive age group, namely 20-35 years, as many as 26 people $(59.1 \%)$, meanwhile KEK pregnant women aged $<20$ years as many as 15 people (34.1), and received the least amount of additional food in the age group $>35$ years, there were 3 people $(6.8 \%)$. Meanwhile, maternal gestation at the beginning of receiving supplementary food KEK pregnant women, most were in trimester 2 and 3, as many as 28 people $(63.6 \%)$, and the rest were in trimester 1 , as many as 16 people $(36.4 \%)$. Furthermore, the additional food types received by KEK pregnant women, that is 44 people $(100 \%)$ are in the layer biscuits form. There are no other types of additional food.

Supplementary food for KEK pregnant women is more distributed and received in July-August 2018 as many as 14 people (31.8\%), in April-June, as many as 12 people $(27.3 \%)$, in September - November there were 12 people (27.3\%) and at least in January - March 2018 there were 6 people (13.6\%). Moreover, supplementary food amount given to KEK pregnant women if adjusted for trimester pregnancy, that is; first trimester 1 receives two doses (4 packs) for 90 days ( 1 month) and second and third trimesters receive three doses (6 packs) during 90 days ( 3 months). Based on the amount suitability given, as many as 30 people $(68.2 \%)$ who gave MT were not suitable, while as many as 14 people $(31.8 \%)$ who were suitable with supplementary biscuits number. Additional food distributed to KEK pregnant women varies in number, some 22 respondents (50\%) who received MT Program for KEK pregnant women as much as 1-2 dos (<990 packs) and another part, 22 people $(50 \%)$ who received $\mathrm{PMT} \geq 3$ dos ( $\geq 90$ packs). Beside, additional food for pregnant women is stored more in closed containers such as jars, as many as 23 people $(52.3 \%)$, in dos packs as many as 15 people $(34.1 \%)$ and some save it by placing it in unopened containers as much as 6 people $(13,6 \%)$. However, people who consume additional food for KEK pregnant women, are consumed by pregnant women alone as many as 38 people $(86.4 \%)$, while those consumed by non-pregnant women are other household members such as children and husbands of pregnant women as many as six people $(13,6 \%)$. Meanwhile, 40 pregnant women $(90.9 \%)$ received an explanation of how to prepare MT, while four pregnant women did not receive an MT preparation from health workers. Besides, Table 9 shows information that there were 41 people $(93.2 \%)$ who prepared supplementary food directly eaten because it was a biscuit groomed, and as many as three people (6.8\%) prepared additional food by mixing it with water/tea/milk first before consuming it.

Also, trimester one pregnant women who consumed two additional pieces of food per day were 12 people $(27.3 \%)$ 
and $>2$ pieces per day were four people $(9.1 \%)$. Whereas for pregnant women whose gestational age enters the $2 \mathrm{nd}$ and third trimesters, as many as 14 people $(31.8 \%)$ consume one additional food per day. While others consume $>1$ pack per day as many as 13 people (29.5\%), and <1 pack / day only 1 person $(2.3 \%)$. Moreover, there are 37 pregnant women $(84.1 \%)$ who like extra food in the form of biscuits, but there are also as many as seven pregnant women (15.9\%) who do not like the taste. It is because the middle part of the biscuits tastes too sweet. While, after supplementary food interventions for 1 - 3 months, pregnant women who were previously KEK 44 people, at the end of the intervention, LILA was $\geq 23.5 \mathrm{~cm}$, which showed good health conditions of 20 people $(45.5 \%)$, and those still LILA $<23.5 \mathrm{~cm}$, the condition of Chronic Energy Deficiency (KEK) of 24 people $(54.5 \%)$. Furthermore, pregnant women who gained weight after consuming supplementary food, 34 people (77.3\%) gained weight, and there were ten people $(22.7 \%)$ who did not gain weight. Meanwhile, as many as 37 people $(84.1 \%)$ did not have complaints after consuming additional food, but as many as seven people (15.9\%) had complaints after consuming supplementary food for pregnant women. Complaints felt by pregnant women after consuming additional food in nausea were five people (11.3\%), dizziness as much as one person $(2.3 \%)$ and too sweet taste as much as one person $(2.3 \%)$. How to deal with complaints after supplementary food consumption that is treated at the health centre one person $(2.3 \%)$, ask for a medication from the village midwife $(2.3 \%)$ and as many as seven people $(11.3 \%)$ for which there is no action.

\section{Results of Monitoring Supplementary Food for Thin Toddlers in South Halmahera Regency}

The children age group under five who received supplementary food (MT) was higher in children aged 1259 months by 41 people $(91.1 \%)$ and lowest at the age of 612 months by four people (4\%). Meanwhile, MT giving schedule for under-fives was higher in January 2018 by 14 $(31.1 \%)$ people and lowest in September-November was eight people (17.8\%). Furthermore, the MT type obtained by all toddlers is 45 biscuits (100\%). While there are a small number of toddlers, who get other MT types such as milk, milk and green beans, milk and Curcuma syrup in a row as much as $3(6.7 \%), 3(6.7 \%)$ and 2 (4.4\%). The MT suitability number given to toddlers is more than half of 27 toddlers $(60 \%)$, not suitable compared to the MT number that is appropriate as many as 18 toddlers $(40.0 \%)$. More than half of MT received by under-fives received MT $\geq 3$ dos of $30(66.7 \%)$ and the remaining 1-2 doses of 15 $(33.3 \%)$. Most of the MT storage areas in closed containers were 32 people $(71.1 \%)$. Whereas the lowest MT storage area for plastics was two people $(4.4 \%)$. The MT majority were consumed by underweight toddlers of 33 people (73.3\%), a small portion consumed by other household members such as brother, sister, mother, cousin, and family as many as 12 people (26.7\%). The respondent majority received an explanation of how to prepare MT as many as 42 people $(93.3 \%)$ and as many as three people $(6.7 \%)$ never received an explanation of how to prepare an MT. The respondent majority prepared MT by giving 36 children directly $(80.0 \%)$, as many as nine people $(20.0 \%)$ how to prepare MT mixed with water/tea/milk. The age group of 611 months of MT administration in 2 packs and > 2 packs per day is two people each $(4.4 \%)$.

Whereas in the 12-59 months age group, three packs were higher per day as many as 22 people $(48.9 \%)$ and lowest > 3 packs per day were eight people $(17.8 \%)$. The MT preferences of most toddlers like to consume MT as many as 38 people $(84.4 \%)$ and only a small toddlers proportion do not like MT consumption as much as seven people $(15.6 \%)$. The nutritional status of children under five $(\mathrm{BB} / \mathrm{U})$ after consuming $\mathrm{MT}$ experienced a minimum increase in weight, according to $\mathrm{BB} / \mathrm{U}$ (proper nutrition) of 13 toddlers $(28.9 \%)$. While those who did not gain a minimum weight gain according to $\mathrm{BB} / \mathrm{U}$ (malnutrition) were 32 infants $(71.1 \%)$. Toddlers who experienced weight gain after consuming MT were 42 toddlers (93.3\%), whereas toddlers who did not gain weight after consuming MT were three toddlers $(6.7 \%)$. A total of 41 toddlers $(91.1 \%)$ who did not experience complaints after consuming MT. Whereas four toddlers $(8.9 \%)$ experienced complaints after consuming MT. The complaints felt type by toddlers after consuming MT are diarrhea of 2 toddlers $(4.4 \%)$ and those who have difficulty defecating as many as two toddlers $(4.4 \%)$. The way to overcome complaints after consuming MT is two toddlers $(4.4 \%)$ who have no action, one toddler $(2.2 \%)$ who is cared for at the health center and one toddler $(2.2 \%)$ who is traditionally treated.

\section{Discussions}

Supplementary feeding for nutrition prone groups is one of the programs implemented by local governments to overcome chronic energy deficiency problem in pregnant women and infant malnutrition status. Additional food provided in factory-processed biscuits form was distributed directly to the main area of KEK pregnant women and thin toddler high cases that is in South Halmahera Regency. The distribution process is directly from the center to the district health office, continued to the Puskesmas and distributed to the target through the Posyandu schedule and visiting the target house. Information on MT reception schedule at Puskesmas, through oral information and who did not get prior notice as experienced by the Indong Puskesmas.

Feasibility of MT storage facilities and infrastructure at Puskesmas in terms of cleanliness, ventilation, humidity, the roof does not leak, capacity, storage method, piles of cardboard, pallets, separate storage of hazardous materials, separate damaged storage, with good category (> 80\% -100 $\%)$ in 4 Puskesmas; Labuha, Bibinoi, Loleo Jaya and Bajo while the category is quite good $(>60-80 \%)$ in the Babang, Indong, and Jiko and the category does not meet the MT storage eligibility requirements $(<60 \%)$ in Gandasuli and Indari Puskesmas.

Monitoring procedures for receiving, distributing and administering reporting Supplementary foods at Puskesmas level are mostly in compliance with reasonable procedures (> 80-100\%), that is timely receipt, quantities and types received in accordance with the goods delivery letter (SPB), KEK pregnant women target and toddler 6-59 months, and have a planned MT administrative file. However, there is 1 
Puskesmas where the procedure is still not suitable $(<60 \%)$, that is in Jiko Puskesmas, which is still lacking in warehouse administration and distribution plans.

The supplementary nutrition intervention program monitoring results in nine Puskesmas working areas in South Halmahera Regency found a schedule for supplement distribution for KEK pregnant women and skinny toddlers vary. Distribution schedule additional food is more distributed in mid-2018 for KEK Pregnant Women from July to November 2018, while additional food for malnourished children is distributed most at the beginning of 2018 in January - August 2018 on the Posyandu schedule.

\section{Overview of Distribution of Supplementary Food for Pregnant Women KEK}

Supplementary foods for pregnant women is nutritional supplementation in layer biscuits form made with unique formulations and fortified with vitamins and minerals given to KEK pregnant women to meet nutritional need 4 packs $=$ 60 packs for 90 food days, per day given 2 pieces $=40 \mathrm{gr}$, and pregnant women trimester 2 and 3 given 3 dos 6 packs $=90$ packs for 90 food days, per day given 1 pack $=3$ pieces $=60$ piece grams. The pregnant women MT distribution carried out in South Halmahera Regency was right on target, that is pregnant women who experienced less Chronic Energy with LILA $(<23.5 \mathrm{~cm})$. Respondents were 44 people with productive age (20-35 years) who experienced the most KEK as many as 26 people $(59.1 \%)$, and most were in the 2 nd and third trimester of pregnancy, that is 28 people $(63.6 \%)$. The MT number given to pregnant women at most does not match gestational age of 30 people $(68.2 \%)$, so that the MT number received by pregnant women, there are weaknesses and excess distribution on target. This is evident from MT number received by $50 \%, 1-2$ dos $(<90$ packs) and $50 \% \geq$ three dos ( $\geq 90$ packs). Regarding the storage place for pregnant women MT, most have used closed containers, 23 people $(52.3 \%)$ and 15 people $(34.1 \%)$ in their packages the rest put them in unclosed containers on the table. The MT Preparation of pregnant women mostly eaten as many as 41 people $(93.2 \%)$, and some mix it first with water/tea/milk as many as three people $(6.8 \%)$. While MT food portion, for trimester 1 pregnant women who consume 2 pieces per day are 12 people $(27.3 \%)$. This means they have consumed according to the correct instructions. As for pregnant women, trimester 2 and 3 who consume MT well, one pack per day are 14 people $(31.8 \%)$. The Utilization of MT Pregnant women provides adequate nutrition with LILA indicators $>23.5 \mathrm{~cm}$, which is as many as 20 people $(45.5 \%)$ whose status is normal after the intervention. However, 24 pregnant women were still in KEK conditions after the intervention $(54.5 \%)$. As for those who gained weight more entered the ages of trimesters 2 and 3 as many as 34 people (77.3\%). The pregnant women MT also had an effect on some pregnant women with complaints of nausea as many as five people (11.3\%), one person who experienced dizziness $(2.3 \%)$ and some complained about the taste that was too sweet one person $(2,3 \%)$. It caused as many as seven pregnant women $(15.9 \%)$ did not like to eat MT given. However, most still like the taste, 37 people $(84.1 \%)$. Efforts were made to overcome complaints, mostly there were no actions of 5 people $(11.3 \%)$, requested medication from the midwife one person $(2.3 \%)$ and also one person $(2.3 \%)$ who was treated at Puskesmas.

\section{Overview of Distribution of Toddler Skinny Supplement Food (less BB)}

Toddler Supplement is nutritional supplementation in supplement food biscuits form with unique formulation and fortification with vitamins and minerals given to infants and toddlers aged 6-59 months in the thin category. For infants and children aged 6-24 months, this supplementary food is used together with complementary foods for mother's milk (MP-ASI). Each primary package (4 pieces/40 grams) toddler supplement food contains a minimum of 160 Calories, 3.2-4.8grams protein, 4-7.2grams fat. The MT for babies 6-11 months gets supplement two dos 12 packs $=180$ packs for 90 food days, per day, has given two packs. Whereas Children 12 - 59 months get MT 3 dos 18 packets $=270$ packs for 90 food days, per day has given three packs. Monitoring the utilization of MT under-fives in South Halmahera Regency, the target of underweight toddlers is more in $12-59$ months age group, as many as 41 people (91.1\%) who receive MT program. However, there were also other MT efforts by local health workers by giving milk, green beans or Curcuma syrup as many as eight people $(17.8 \%)$ whose funds came from BOK funds. The toddler MT distribution receipts is based on the number of the gifts with toddler age, there are still many do not match the amount, that is 27 people $(60 \%)$, and 18 people $(40 \%)$ are following amount receipt based on child age. Therefore, there is a difference MT received the number, as many as 30 people $(66.7 \%)$ received $>270$ packets for 90 days and there were 15 people $(33.3 \%)$ who received MT only $1-2$ dos ( $<180$ packs) for 90 days.

Most of the respondents who received MT Toddlers did MT storage in closed containers, 32 people $(71.1 \%)$, but there were also those who still stored in their dos/packages 7 people $(15.6 \%)$, and other places that were not closed 4 people $(8.9 \%)$ and plastic 2 people $(4.4 \%)$. The MT toddler is not only consumed by thin toddlers but other family members such as brother, sister, mother. In the household also consume MT as many as 12 respondents (26.7\%). Most respondents $(93.3 \%)$ had received information on how to prepare MT by health workers and as many as 36 people $(80 \%)$ how to prepare MT by directly giving MT to children; besides, nine people (20\%) prepared MT by mixing it first with water/tea/ milk. The portion of MT giving for babies 6-11 months as many as two people $(4.4 \%)$ has given MT according to its portion which is two pieces per day, while for toddlers $12-59$ months as many as 22 people $(48.9 \%)$ who have MT consumption as much as three packs per day. This also provides information that MTs are more favored by toddlers $(84.4 \%)$, whereas $15.6 \%$ do not like MT.

The MT programs provision Impacts for underweight toddlers provides a change in children nutritional status who were previously in a poor nutritional condition. After the 3month intervention, there were 13 children (28.9\%) who experienced an increase in functional nutritional status, 


\section{ACKNOWLEDGMENT}

wile 32 people $(71.1 \%)$ had not gained a minimum weight gain based on BW/U (malnutrition). Moreover, from the toddler weight gain after consumption most $(93.3 \%)$ who have gained weight. The MT consumption can also cause some complaints such as diarrhea and defecation, which is experienced by 4 toddlers $(8.8 \%)$, and efforts made to overcome these complaints in no action $(4.4 \%)$, traditional treatment for example by using herbal plants $(2.2 \%)$ and some are also treated at Puskesmas (2.2\%).

\section{CONCLUSION}

a. The supplementary food (MT) distribution description for KEK pregnant women and underweight toddlers at Puskesmas level has mostly fulfilled reasonable procedures (> 80$100 \%$ ), that is timely receipt, quantities and types received according to the goods delivery letter (SPB), there are target data for KEK pregnant women and Toddler 6-59 months, and have a planned MT administrative file.

b. The supplementary food storage (MT) Description for KEK pregnant women and underfives at Puskesmas level that have fulfilled the requirements in good categories (> 80\% $100 \%$ ) found in Labuha, Bibinoi, Loleo Jaya and Bajo, while the category is quite good (>60-80\%) in the Babang, Indong and Jiko, and did not meet the eligibility requirements category for MT storage $(<60 \%)$ in Gandasuli and Indari.

c. The supplementary food (MT) impact description on the increase in LILA by 20 people $(45.5 \%)$ whose status becomes normal $(\mathrm{MUCH}>23.4 \mathrm{~cm})$ and or weight (BB) for KEK pregnant women has increased by BB by 34 people $(77.3 \%)$.

d. The supplementary feeding (MT) impact description on weight gain (BB) of underweight toddlers as many as 13 people $(28.9 \%)$ whose condition has improved, 32 people $(71.1 \%)$ is still malnourished. However, as many as $93.3 \%$ increases in BB after MT consumption.

e. The increase in LILA and weight gain also affects some pregnant women with nausea complaints as many as five people $(11.3 \%)$, one person who experiences dizziness $(2.3 \%)$ and some complained about the sweet taste of 1 person $(2.3 \%)$. It caused as many as seven pregnant women $(15.9 \%)$ did not like to eat MT given in biscuits form, most still like the taste, 37 people (84.1\%). Whereas in thin toddlers, MT consumption can also cause several complaints such as diarrhea and difficulty defecating, which is experienced by four toddlers $(8.8 \%)$.
Thank you to the Rector of Universitas Muhammadiyah Maluku Utara for support and assistance. To all who have to assist for this research was acknowledged.

\section{REFERENCES}

[1] Gui M, Indonesia D. Nutrition problems in Indonesia. 2005;28(2):43-55.

[2] Elferink-Gemser MT, Smith J, Visscher C. year old, typically developing children: A systematic review. J Sci Med Sport [Internet]. 2014;9. Available from: http://dx.doi.org/10.1016/j.jsams.2014.09.007

[3] Hair NL, Hanson JL, Wolfe BL, Pollak SD. Association of Child Poverty, Brain Development, and Academic Achievement. 2015;53706(9):822-9.

[4] 4Ruel MT, Alderman H, Nutrition C, Group S. Maternal, and Child Nutrition 3 Nutritionsensitive interventions and programs : how can they help to accelerate progress in improving maternal and child nutrition? Lancet [Internet]. 2013;6736(13):1-16. Available from: http://dx.doi.org/10.1016/S01406736(13)60843-0

[5] Victora CG, Adair L, Fall C, Hallal PC, Martorell R, Richter L, et al. Maternal and Child Undernutrition 2 Maternal and child undernutrition: consequences for adult health and human capital. 2008;371:340-57.

[6] Alqahtani A, Elahmedi M, Qahtani AR Al. Laparoscopic Sleeve Gastrectomy in Children Younger Than 14 Years Refuting the Concerns. 2015;312-9.

[7] Cheng Y, Dibley MJ, Zhang X, Zeng L, Yan H. Assessment of dietary intake among pregnant women in a rural area of western China. 2009;9:1-9.

[8] Condon EM, Crepinsek MKAY, Fox MKAY. School Meals: Types of Foods Offered to and Consumed by Children at Lunch and Breakfast. YJADA [Internet]. 2009;109(2): S67-78. Available from: http://dx.doi.org/10.1016/j.jada.2008.10.062 
[9] Uauy R, Kain J. The epidemiological transition: need to incorporate obesity prevention into nutrition programs. 2017;5:223-9. 